\title{
Mobile Learning Application for Helping Pupils in Learning Chemistry
}

\author{
https://doi.org/10.3991/ijim.v15i01.11897
}

\author{
Ahmed Ewais $(\bowtie)$ \\ Arab American University, Jenin, Palestine \\ Vrije Universiteit Brussel, Brussel, Belgium \\ aewais@aaup.edu, aewais@vub.be \\ Rami Hodrob, Mohammed Maree, Sireien Jaradat \\ Arab American University, Jenin, Palestine
}

\begin{abstract}
Elementary school pupils can face different difficulties to learn different topics. Among the different topics, learning chemical elements and their different properties and interactions. A way to make the learning process easier and effective is using mobile learning. Mobile learning can contribute a new method to educate pupils different topics. Also, mobile learning has different advantages over classical learning materials. Among the different advantages of using mobile learning is the fact that it enables pupils to interact with learning materials, visualize different learning concepts, and learning anytime and anywhere. This article presents an exploration study related to investigating the possible use of educational mobile App to learn chemistry course in elementary school. The article presents also a qualitative research methodology implemented by including 7 pupils. The findings of this research show that mobile learning technology can be adopted for learning chemistry course in order to enable pupils to understand periodic table, chemical elements properties and their chemical interaction. Also, this study has shown that the proposed mobile application can be integrated in learning chemistry course for elementary school pupils.
\end{abstract}

Keywords-Usability; Mobile Learning; Chemistry; Elementary School

Students

\section{Introduction}

Although Chemistry is considered as one of the important science subjects in elementary schools, pupils find it as uninteresting and difficult domain (Sirhan, 2007). This is related to the obstacles and misconception that the pupils face to understand learning concepts such as periodic table, properties of chemical elements, chemical interaction between different atoms and molecules, chemical bound, etc. For instance, chemical bond can be considered as an abstract concept which cannot be mapped or applied to everyday life (Palmer, 2001). Therefore, misconception can have a direct negative effect to pupils learning and it can interfere with pupils understanding and accordingly their learning achievements. 
Therefore, different solutions were proposed by researchers to help pupils in learning chemistry course and to improve their learning achievements. Among the possible solutions, researchers proposed the use of educational mobile Apps and Augmented Reality educational mobile Apps. For instance, (Hafis \& Supianto, 2018) proposed mobile application game which enables pupils to learn chemistry concept of chemical bonds to improve the pupils learning achievements. Another research work presented in (Cahyana, Paristiowati, Savitri, \& Hasyrin, 2017) proposed the use of mobile learning application to visualize the different steps in organic chemistry reaction by enabling pupils to compose the chemical bonds between atoms using touch screens. The evaluation results showed that mobile learning had a positive effect on pupil learning outcomes when the pupils have high learning independence. More related work can be found in the reviewed work in (Klimova, 2019; Qurat-ul-Ain et al., 2019).

Concerning the use of Augmented Reality technology, there are a number of solutions were proposed to help pupils in understanding different educational topics (Ahmed Ewais; Olga De Troyer, 2019; Ewais, De Troyer, Arra, \& Romi, 2019; Figueiredo, Gomes, Gomes, Gaspar, \& Lopes, 2018; Toledo-Morales \& SanchezGarcia, 2018; Yang, Mei, \& Yue, 2018). For instance, researchers (Toledo-Morales \& Sanchez-Garcia, 2018) propose the use of AR technology in understanding topics that are related to earth representation. The results showed that the use of educational AR mobile Apps in teaching and learning was perceived as positive and facilitator in the acquisition of the required knowledge about the topic. Another related work presented in (Ewais et al., 2019) showed positive feedback from pupils toward the use of educational AR mobile App in learning chemistry in elementary schools. More research work related to proposing educational AR mobile Apps can be found in (Sirakaya \& Alsancak Sirakaya, 2018).

Readiness and willingness of pupils in using mobile learning are also investigated thoroughly in the literature. A number of studies revealed that there are a number of factors that can influence the actual use of mobile learning. For instance, it was mentioned that perceived usefulness, perceived ease of use, attitudes towards mobile learning, and intension to use mobile learning were all considered as significant predictors for the use of mobile learning (Chuchu \& Ndoro, 2019; Qurat-ul-Ain et al., 2019). Also, based on study presented in (Wasif Nisar, Munir, \& Shad, 2011), the availability and usage of ICT can improve pupils' knowledge and learning skills.

Our work aims at helping pupils in learning chemistry using mobile learning App which provides Arabic learning materials. There are different reasons for focusing on providing learning materials in Arabic language to learn chemistry and focusing on female pupils. The justification is considered as follow:

First, the need for providing pupils with learning materials in their mother language was highlighted in literature. For instance, among the different difficulties that the pupils face in learning chemistry is the language. Researcher (Sirhan, 2007) highlighted that language and communication are considered as one of the factor that affect the information overloading. Therefore, it is important to support pupils in Palestine with mobile learning Apps that explains the different concepts of Chemistry in Arabic language. In general, there is a limited number of mobile learning applications including learning materials in Arabic language. Accordingly, there is a limited number of studies 
which proposed mobile learning for pupils to help pupils in learning chemistry course. A number of attempts can be recorded to (Al-Razgan \& Alotaibi, 2019; Ewais et al., 2019).

Second, the focus is on female pupils because in general they show less interest in learning chemistry than male pupils (Kubiatko, 2015). In addition, a recent world bank report (The World Bank, 2018) stresses the need to encourage female pupils to complete their 12 years of education as this can increase economic benefits. Also, male pupils, in general, have a good experience with mobile learning Apps (Cai, Wang, \& Chiang, 2014; Johnson, Smith, Willis, Levine, \& Haywood, 2011; Lee, 2012). On the other hand, female pupils are less familiar with mobile learning Apps. Therefore, it is quite important to specifically investigate female pupils' attitudes toward the use mobile learning Apps as a negative attitude may have a direct impact on their learning achievements.

Therefore, this study is useful on the following aspects. First, supporting elementary school pupils with innovative mobile learning App can diminish different difficulties related to learning chemistry. Second, it contributes to the literature in providing mobile learning solutions with Arabic contents.

The article is structured as follow: Section 2 gives explanation about the research objectives and research questions to be answered in this research work. It also explains the different components of the proposed mobile learning framework as well as principles to be considered in developing mobile learning applications. After that it explains the different functionalities and features that are provided in the developed mobile learning App. The following section shows information about the participants who were included in the evaluation, details about the adopted instrument and the three steps performed in the evaluation. After that section 4 presents the obtained results from the participants (pupils). The last section concludes this article and highlights future work.

\section{Methods and Materials}

This section presents the research objectives, research questions, and brief explanation about the developed mobile learning application.

\subsection{Research objective and questions}

The main goal of this research work is twofold. First, the research work will determine preferred and interesting features for mobile learning App to learn chemistry course. Second, this research work will identify pupils' experiences in using mobile learning App for learning chemistry course. Accordingly, this research work will answer the following research questions

- What are the interesting and preferred features in mobile learning App for learning chemistry course in a Palestinian elementary school? 
- What are female pupils' attitudes towards using mobile application to learn chemistry course in a Palestinian elementary school?

\subsection{ChemApp mobile learning application}

To be able to provide elementary school pupils with mobile application that can be useful for learning chemistry, an android mobile application was developed. The application can be installed in smartphones and tablets that are running android operating system. The mobile application is so-called ChemApp which is a learning tool created to facilitate pupils in learning and overtaking misconception about learning concepts that are related to Chemistry course.

ChemApp includes learning contents and functionalities that are provided to support pupils in their learning process. The learning contents includes explanation based on the lessons that are available in the course's book. The explanation is created using whiteboard animation technique. This technique is mainly done by authors who physically draws, brushes and records illustrations for specific concepts using a whiteboard surface and marker pens. The animations are also aided with script narration. Furthermore, a number of functionalities related to games, interactive learning contents, and quizzes are also integrated in the application.

To be able to create learning contents and support the application with different functionalities, a number of IDEs have been considered. For instance, Adobe Audition has been used to record audio files and edit some parts to be able to integrate them with animation files. To create whiteboard animation files, VideoScribe software was adopted. Both Photoshop and illustrator were used to draw illustration, graphic characters, graphs. Finally, Unity was also used to integrate the different modules inside the mobile application. Furthermore, Unity can generate application for different platforms such as iOS and android. C\# scripting language was considered as a programming language for implementing the different functionalities.

The main interface of the applications (see Figure 1) is divided to two parts. First part (upper canvas highlighted in blue rounded rectangle) includes 8 lessons created using whiteboard animation and second part (lower canvas highlighted in orange rounded rectangle) includes a number of modules: interactive periodic table, chemical reaction equations, interactive chemical lab, electron configuration, and molecules game. It also has a hint bar which displays some notes that are available for each lesson in the course's book. Furthermore, the learner can mute music sound that is played once the ChemApp is lunched. 

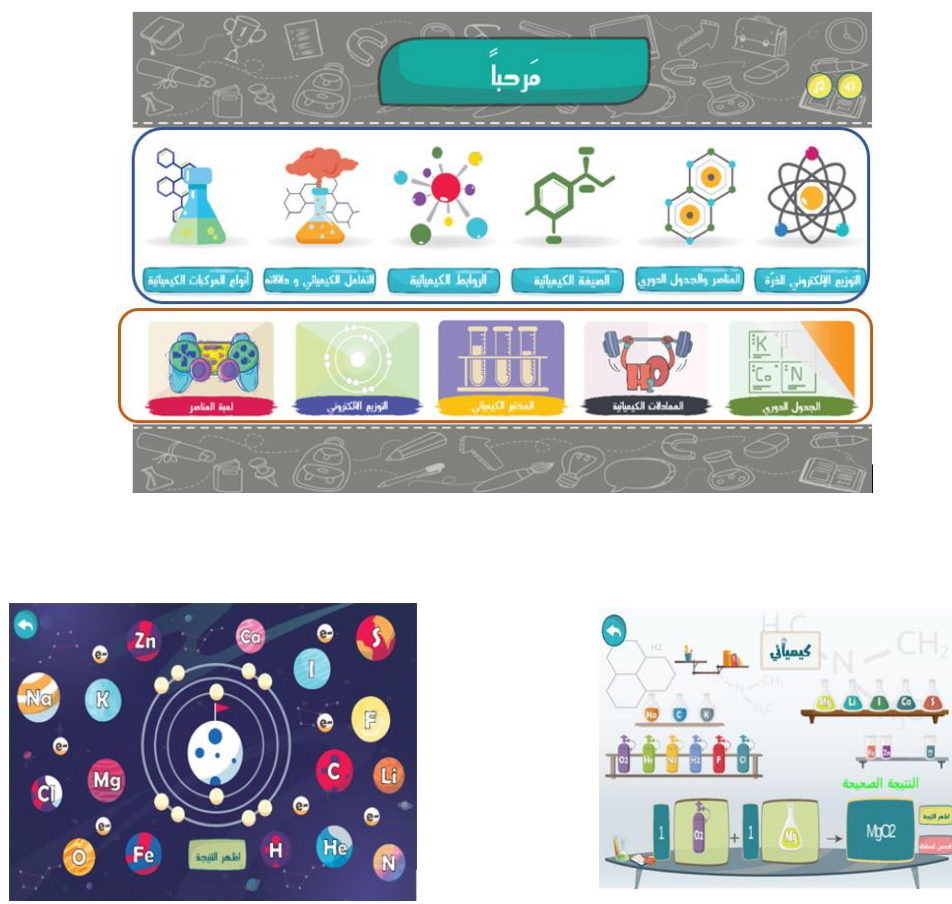

Fig. 1. Screenshots of ChemApp

\section{$3 \quad$ Methodology}

\subsection{Sample}

The evaluation was carried out with 7 female pupils of one Palestinian primary school in Jenin. The pupils were 13-14-year-old and in a class of the 8th grade. All the pupils were following a chemistry course. According to the research objective, only female pupils were considered in this evaluation. It is important to mention that the pupils were informed that the participation in the evaluation is volunteer and they were not obligated to participate in the evaluation. Furthermore, they would not be marked for their evaluation and the questionnaire results will be anonymous. Demographic detail about the participants is given in section 4.1.

\subsection{Instrument}

To be able to reveal subjective evaluation, a number of questions were already formulated before conducting the evaluation. The paper authors reviewed a number of related work such as (Alqahtani \& Mohammad, 2015; Cai et al., 2014) to formulate the 
interview questions. Accordingly, a number of questions were compiled for pupils' interview. The questions and their results are presented in section 4.2 and section 4.3.

The formulated questions were reviewed and approved by a group of referees who were asked to revise them. Moreover, 5 chemistry teachers were involved in giving feedback on the questions' wording before conducting the evaluation phase. The given feedback was not only related to questionnaire's wording but also related to improving clarity and the relevance of the questionnaire items to the research idea. At the end, the provided feedback from both referees and teachers was considered and modifications were applied to the questions.

It is important to mention that to be able to have an objective evaluation, a number of scientific steps have been conducted to avoid biased evaluation. For instance, all questions were translated to Arabic language which make it easier for the pupils to give their feedback and opinion correctly and to avoid misunderstanding. Furthermore, the pupils were informed that there are not correct or wrong answers and they were encouraged to provide a formative, objective and critical evaluation to improve and enhance some important aspects related to services' and features' quality, usefulness, etc. Another step was related to writing the questions words with care to avoid leading the participants to give more favorable answers (Lazar, Feng, \& Hochheiser, 2010).

\subsection{Evaluation steps}

The main goal of the evaluation is to obtain some insight thoughts from pupils, that are related to their attitude and current available services and functionalities in the mobile learning App. The evaluation was conducted inside a classroom in a Palestinian school. The evaluation took place during a one-hour session and consisted of the following three steps:

- First step (training phase): as it was not expected that the pupils can interact immediately with ChemApp. Therefore, a 10 minutes introduction was given to the pupils by one of the researchers. She showed the different functionalities that are provided in ChemApp. For instance, she showed pupils how to use the whiteboard lessons videos. Also, she explained how to use the interactive periodic table, chemical reaction equations and interactive chemical lab, electron configuration, and the game.

- Second step (exploration phase): was related to giving the 7 pupils tablets to try out the application during 10 minutes. The pupils interacted, explored, and discussed the different components of ChemApp. Figure 2 shows the pupils trying out the application using tablets. It is important to mention that 5 teachers were observers, but they did not help or give instructions to the pupils during their exploration of the application.

- Third step (interview phase): was related to interviewing pupils using a number of predefined questions. The interview was conducted with the 7 pupils individually. More details about the questions that are used in the interview are already presented in previous section (section 3.2). 

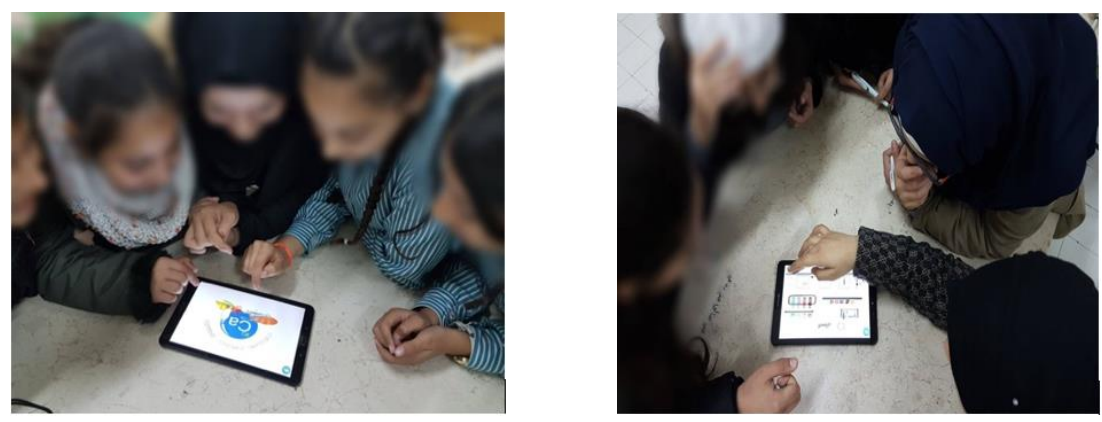

Fig. 2. ChemApp Demonstration

\section{$4 \quad$ Results and Discussion}

This section presents and discusses the obtained results gathered from the interview with the pupils. The purpose of this step was to know pupils' feedback about the educational mobile application. Therefore, a number of questions were asked to pupils. The interviews were conducted after filling out the questionnaire which was distributed to the pupils as mentioned in previous section. Number of participants in the interview were 7 pupils. Next is explanation for the results obtained from the interview with the pupils.

\subsection{Participants data}

Concerning the results related to the demographic data about participants, the 7 pupils have almost a homogeneous background about using mobile technology in learning process. For instance, the question "Do you know mobile learning technology?" was 7 participants with positive answer. Moreover, more than $50 \%$ (4) of the pupils are using the mobile phone or smartphone on daily basis. However, the majority of the participants (6 participants) are not using educational mobile applications most often. Such result is expected because of the limited number of available educational mobile applications that helps pupils to understand learning topics related to their school courses.

\subsection{Pupils interview results}

All (7) pupils answered the question "Do you think this mobile application facilitate chemistry learning?" with positive feedback which shows some appreciations comments for the use of the mobile application in the context of the chemistry course. For instance, an appreciation comment related to providing useful information was mentioned by two pupils. Another feedback, which was mentioned by 3 pupils, was related to the easy to use the ChemApp anytime and anywhere. Other comment was 
related to appreciation for the availability of lesson in whiteboard video format because it helps to improve pupils' conceptions of the fundamental concepts in chemistry. The concepts formation is considered as one of the facets of the learning difficulties related to chemistry (Sirhan, 2007). Therefore, using whiteboard videos can help the pupils to enhance their understanding about the different learning concepts.

Some pupils (2) mentioned that the application was not boredom, it was an effective learning experience for them, and they appreciated the use of games to learn different learning concepts related to chemistry course. Previous results are also confirmed in (Rohendi, 2019). Figure 3 shows the obtained feedback from the pupils concerning question 1.

Pupils' answers to the question "Why do you think this tool is helpful? In what areas does the tool help you?" indicated a high appreciation to the use of mobile learning in studying chemistry course as shown in Figure 4. For instance, 4 pupils mentioned that ChemApp helped them to learn chemistry in a new simple way. Also, 2 pupils think that ChemApp can make learning experience easier and faster as it enables them to learn electronic distribution and learn how to use periodic table in interactive way. Concerning the second part of the question, mathematics and physics were named. The previous answers were also confirmed in the literature (Sirakaya \& Alsancak Sirakaya, 2018).

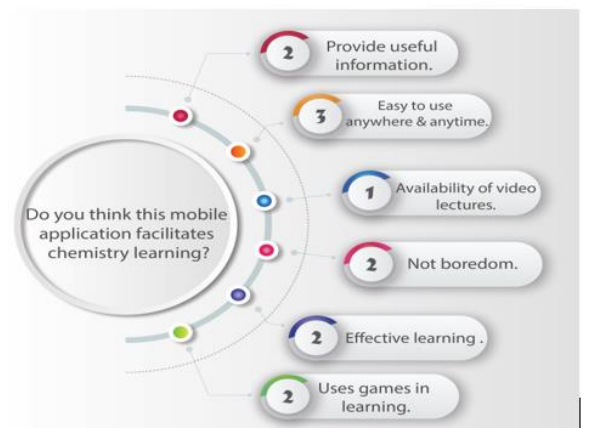

Fig. 3. Responds Summary for Question 1

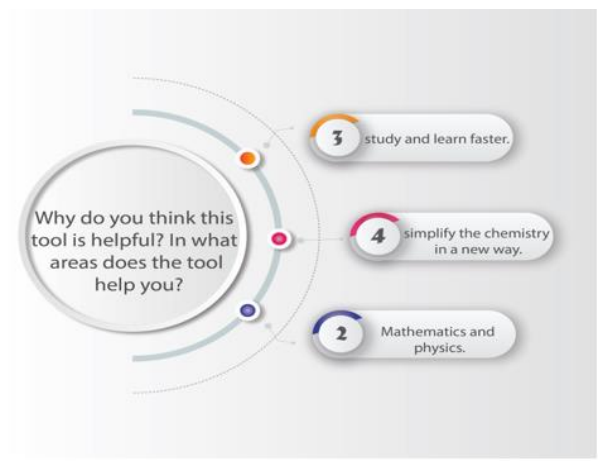

Fig. 4. Responds Summary for Question 2 
In reply to the question "Do you wish to use mobile application to learn chemistry in the future? Why?", all answers were positive. Figure 5 shows different pupils responds in answering the previous question. For instance, 2 pupils mentioned that the available information are interested and interrelated. This encourages them to use the application in the future. This is also confirmed in similar studies (Ahmed Ewais; Olga De Troyer, 2019). Other 4 pupils appreciated the application as it explains the different learning concepts in a simple way. They also mentioned that they can use the application in later study stages as the application help them in understanding a number of fundamentals in learning chemistry. Providing means to help pupils to recall previous knowledge easily was highlighted also in previous study (Sirhan, 2007). Other remark was related to the fact that the pupils were eager to use this new technology (m-learning) in the future (Deris \& Shukor, 2019).

The pupils were encouraged to indicate if they like to learn using mobile applications or desktop applications. All pupils indicated a desire to use the mobile applications (for smartphone and tablets) rather than desktop applications. This is concluded from the pupil's answers on the question "How do you compare this mobile application with other learning tools such as desktop applications." Figure 6 summarizes the obtained feedback from the pupils. For instance, 4 pupils mentioned that they like to use mobile learning because of the ability to combine both learning and entertainment. Other 5 results reasoned in preferring to use the mobile applications as smartphone is available anytime an everywhere. Other appreciation comments related to easy of handling the device (smartphone or tablet) and easy of interactivity functionalities like touch screens.

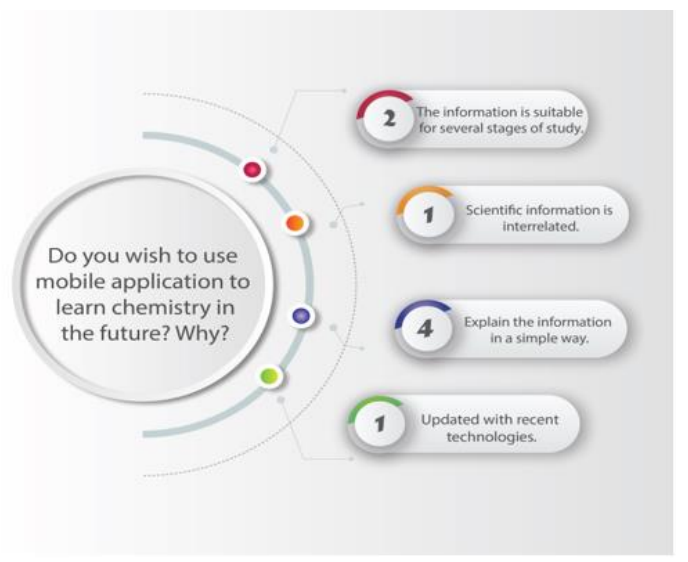

Fig. 5. Responds Summary for Question 3 


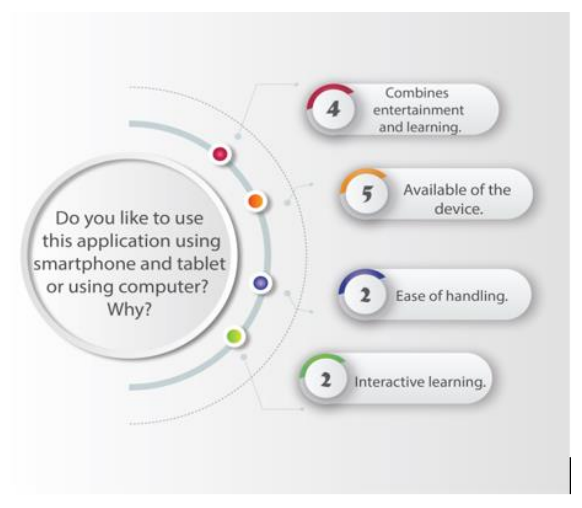

Fig. 6. Responds Summary for Question 4

All 7 pupils answered the question "Do you think this mobile application is better than classical tools (books, tutorials, etc.)" with favor to the use of mobile learning. As depicted in Figure 7, there were 6 comments on this question stated that the pupils think that the ChemApp can provide them with learning content in an innovative way. Furthermore, 2 comments were related to interactivity feature such as interactive periodic table, ease of accessing different video lessons, linking chemical elements with their sources from real environments presented in images. Other 2 comments were related the ease of handling and interacting with ChemApp components. Another feedback from 3 pupils was related to combination of entertainment and learning. Previous advantages and features confirmed the obtained feedback (from 2 pupils) related to the idea that using ChemApp can save time to learn chemistry topics. This is also confirmed in (Ahmed Ewais; Olga De Troyer, 2019).

Pupils answers to the question "Do you think that mobile learning has any disadvantage? What are they?" highlighted a number of interesting improvements. For example, 3 pupils mentioned that it would be better to add more whiteboard videos that explains the different concepts in each lesson (see Figure 8). Also, the videos need to be ordered in a specific learning path. The previous comment was mentioned by 4 pupils.

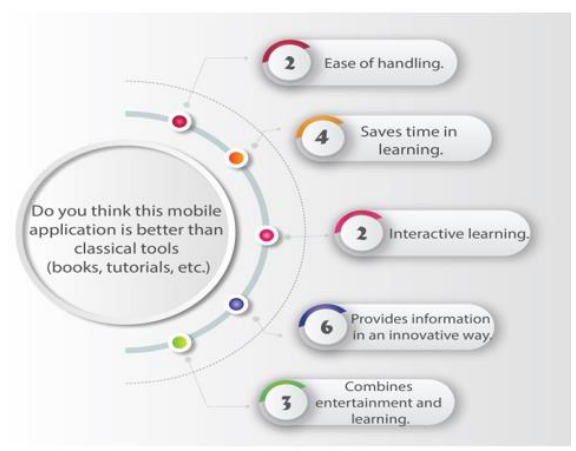

Fig. 7. Responds Summary for Question 5 


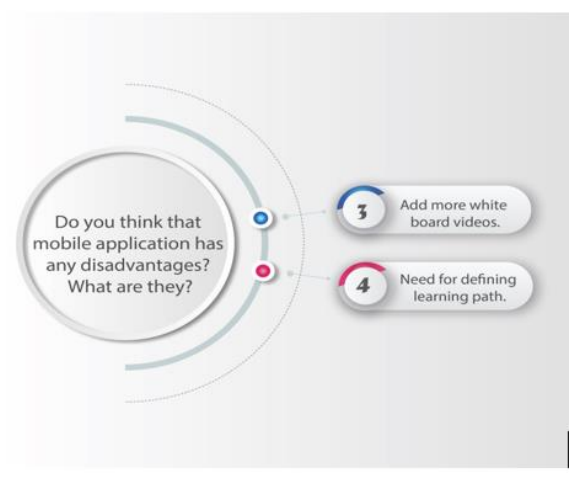

Fig. 8. Responds Summary for Question 6

Finally, the pupils were asked to give some advices, for improving the mobile learning experience, by asking them the question "Can you offer some advice for improving this learning tool?". Figure 9 shows the different advices that were given by the pupils. Following some previous comments, one pupil thought adding learning path is an important improvement to the application. Other two pupils would like to see more educational games that are integrated to the application. Similar to previous remarks about adding more whiteboard videos, one pupil mentioned that it would be nice to have a whiteboard video for each element in periodic table. Other two pupils pointed to the need to add more chemical reaction equations to the application.

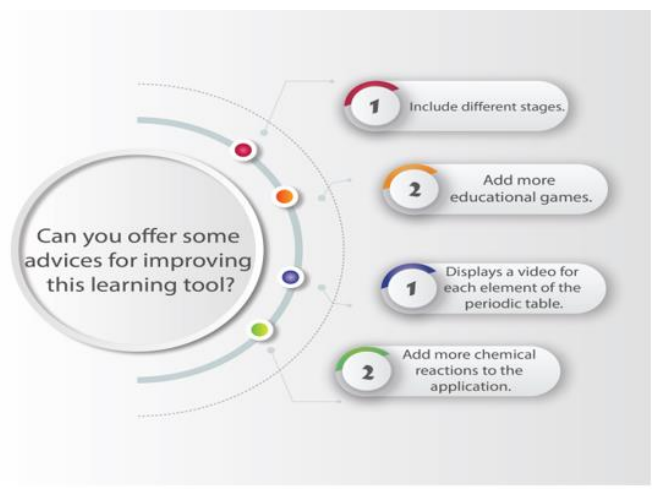

Fig. 9. Responds Summary for Question 6

\section{Conclusion}

This article presents framework for creating mobile application for educational purposes. Furthermore, a developed mobile application for learning chemistry course was explained and evaluated. The ChemApp consists of a number of components that facilitates learning process of pupils. The components are whiteboard videos allowing pupils to watch explained book's lesson in Arabic language; interactive periodic table 
enabling pupils to view all chemical elements in the periodic table with their characteristics; chemical reaction equations and interactive chemical lab helping pupils to perform chemical equations between different elements; electron configuration enabling pupils to know how many electrons that are available for each chemical element; molecules game.

The ChemApp was evaluated by female pupils to test its functionalities and investigate pupils' attitudes toward the use of mobile learning in chemistry course. Based on the obtained results, it can be concluded that female pupils appreciate the use of the proposed mobile learning App (ChemApp). Although, the learning effectiveness was not investigated in this study, some results revealed some important aspects such as using mobile learning can help pupils in understanding abstract learning concepts as it provides visualization to them. Another aspect is related to supporting pupils with chemical lab to understand the results of the interaction between different chemical elements in periodic table.

There are some limitations to this research work, which should be highlighted. The current study was limited to a number of participants from one elementary school. Therefore, further evaluations are required to be conducted with more participants from different elementary schools. Another limitation is related to teachers' involvement in further studies. Previous studies are required to investigate possible resistance from teachers in using mobile technology as a teaching material, which can make it as one of the obstacles in adopting mobile learning for pupils.

For future research work, enabling teachers to create learning materials that supports their teaching strategies is an important aspect that still need more efforts by researchers. For instance, there is a need to support teachers with authoring tool that enable them to create, customize, deploy and integrate learning materials in mobile learning Apps. Furthermore, the authoring tool needs to enable teachers to create different assessments techniques such as quizzes, exams, exercises, etc.

\section{References}

[1] Ahmed Ewais; Olga De Troyer. (2019). A Usability and Acceptance Evaluation of the Use of Augmented Reality for Learning Atoms and Molecules Reaction by Primary School Female Students in Palestine. Journal of Educational Computing Research, 57(7), 16431670. https://doi.org/10.1177/0735633119855609

[2] Al-Razgan, M., \& Alotaibi, H. (2019). Personalized Mobile Learning System to Enhance Language Learning Outcomes. Indian Journal of Science and Technology, 12(1), 1-9. https://doi.org/10.17485/ijst/2019/v12i1/139871

[3] AL Qahtani, M., \& Mohammad, H. (2015). Mobile applications' impact on student performance and satisfaction. Turkish Online Journal of Educational Technology, 14(4), $102-112$.

[4] Cahyana, U., Paristiowati, M., Savitri, D. A., \& Hasyrin, S. N. (2017). Developing and application of mobile game-based learning (M-GBL) for high school student's performance in chemistry. Eurasia Journal of Mathematics, Science and Technology Education, 13(10), 7037-7047. https://doi.org/10.12973/ejmste/78728 
[5] Cai, S., Wang, X., \& Chiang, F. K. (2014). A case study of Augmented Reality simulation system application in a chemistry course. Computers in Human Behavior, 37, 31-40. https://doi.org/10.1016/j.chb.2014.04.018

[6] Chuchu, T., \& Ndoro, T. (2019). An examination of the determinants of the adoption of mobile applications as learning tools for higher education students. International Journal of Interactive Mobile Technologies, 13(3), 53-67. https://doi.org/10.3991/ijim.v13i03. 10195

[7] Deris, F. D., \& Shukor, N. S. A. (2019). Vocabulary Learning Through Mobile Apps: A Phenomenological Inquiry of Student Acceptance and Desired Apps Features. International Journal of Interactive Mobile Technologies (IJIM), 13(07), 129. https://doi.org/10. 3991/ijim.v13i07.10845

[8] Ewais, A., De Troyer, O., Arra, M. A., \& Romi, M. (2019). A Study on Female Students' Attitude Towards the Use of Augmented Reality to Learn Atoms and Molecules Reactions in Palestinian Schools. In International Conference on Augmented Reality, Virtual Reality and Computer Graphics: AVR 2019 (pp. 295-309). https://doi.org/10.1007/978-3-03025999-0_26

[9] Figueiredo, M., Gomes, J., Gomes, C. M. C., Gaspar, R., \& Lopes, J. M. (2018). Augmented reality as a new media for supporting mobile-learning. In Virtual and Augmented Reality: Concepts, Methodologies, Tools, and Applications (Vol. 3, pp. 1625-1643). https://doi.org/10.4018/978-1-5225-5469-1.ch076

[10] Hafis, M., \& Supianto, A. A. (2018). Mobile game design for learning chemical bonds with endless run approach. International Journal of Interactive Mobile Technologies, 12(8), 104112. https://doi.org/10.3991/ijim.v12i8.9260

[11] Johnson, L., Smith, R., Willis, H., Levine, A., \& Haywood, K. (2011). The 2011 Horizon Report. Media. https://doi.org/10.1002/chem.201001078

[12] Klimova, B. (2019). Impact of Mobile Learning on Students' Achievement Results. Education Sciences, 9(2).

[13] Kubiatko, M. (2015). Is chemistry attractive for pupils? Czech pupils' perception of chemistry. Eurasia Journal of Mathematics, Science and Technology Education. https://doi.org/10.12973/eurasia.2015.1444a

[14] Lazar, J., Feng, J. H., \& Hochheiser, H. (2010). Research Methods in Human-Computer Interaction. Wiley Publishing, Inc.

[15] Lee, K. (2012). Augmented Reality in Education and Training. Linking Research and Practice to Improve Learning, 56(2), 13-21. https://doi.org/10.1007/s11528-012-0559-3

[16] Palmer, D. (2001). Students' alternative conceptions and scientifically acceptable conceptions about gravity. International Journal of Science Education, 23(7), 691-706. https://doi.org/10.1080/09500690010006527

[17] Qurat-ul-Ain, Q.-A., Shahid, F., Aleem, M., Islam, M., Iqbal, M., \& Yousaf, M. (2019). A Review of Technological Tools in Teaching and Learning Computer Science. Eurasia Journal of Mathematics, Science and Technology Education, 15(11). https://doi.org/10. 29333/ejmste/109611

[18] Rohendi, D. (2019). Game-Based Multimedia for Horizontal Numeracy Learning. International Journal of Emerging Technologies in Learning (IJET), 14(15), 159. https://doi.org/10.3991/ijet.v14i15.10679

[19] Sirakaya, M., \& Alsancak Sirakaya, D. (2018). Trends in Educational Augmented Reality Studies: A Systematic Review. Malaysian Online Journal of Educational Technology, 6(2), 60-74. https://doi.org/10.17220/mojet.2018.02.005

[20] Sirhan, G. (2007). Learning Difficulties in Chemistry: An Overview. Journal of Turkish Science Education, 4(2), 2-20. 
[21] The World Bank Not Educating Girls Costs Countries Trillions of Dollars, Says New World Bank Report. Washington. Retrieved from https://www.worldbank.org/en/news/pressrelease/2018/07/11/not-educating-girls-costs-countries-trillions-of-dollars-says-new-worldbank-report https://doi.org/10.1596/0-8213-3601-0

[22] Toledo-Morales, P., \& Sanchez-Garcia, J. M. (2018). Use of augmented reality in social sciences as educational resource. Turkish Online Journal of Distance Education, 19(3), 3852. https://doi.org/10.17718/tojde.444635

[23] Wasif Nisar, M., Munir, E. U., \& Shad, S. A. (2011). Usage and impact of ICT in education sector; a study of Pakistan. Australian Journal of Basic and Applied Sciences, 5(12), 578583.

[24] Yang, S., Mei, B., \& Yue, X. (2018). Mobile Augmented Reality Assisted Chemical Education: Insights from Elements 4D. Journal of Chemical Education, 95(6), 1060-1062. https://doi.org/10.1021/acs.jchemed.8b00017

\section{Authors}

Ahmed Ewais is from the Computer Science Department, Arab American University, Jenin, Palestine and Web \& Information System Engineering Laboratory, Department of Computer Science, Vrije Universiteit Brussel, Belgium. Email: aewais@ aaup.edu / aewais@vub.be

Rami Hodrob is from Computer Science Department, Arab American University, Jenin, Palestine

Mohammed Maree works in Multimedia Department, Arab American University, Jenin, Palestine

Sireien Jaradat works in Multimedia Department, Arab American University, Jenin, Palestine

Article submitted 2019-10-17. Resubmitted 2020-10-20. Final acceptance 2020-10-21. Final version published as submitted by the authors. 